\title{
Hypodopaminergic polygenic risk for polysubstance use.
}

\author{
Joelle A Pasman ${ }^{1 *}$, Karin JH Verweij ${ }^{1}$, Jorien L Treur ${ }^{1}$, Gonneke Willemsen ${ }^{2}$, Jouke-Jan Hottenga ${ }^{2}$, Judith \\ R Homberg ${ }^{3}$, Sabine Spijker ${ }^{4}$, Roy Otten ${ }^{5,6}$, Rutger CME Engels ${ }^{7}$, Eco JC de Geus ${ }^{2,8}$, Jacqueline M Vink ${ }^{1}$ \\ ${ }^{1}$ Developmental Psychopathology, Behavioural Science Institute, Radboud University Nijmegen, Nijmegen, The \\ Netherlands \\ ${ }^{2}$ Department of Biological Psychology, Faculty of Behavioural and Movement Sciences, Vrije Universiteit \\ Amsterdam, Amsterdam, The Netherlands \\ ${ }^{3}$ Department of Cognitive Neuroscience, Donders Institute for Brain, Cognition and Behaviour, Radboud \\ University Nijmegen Medical Centre, Nijmegen, The Netherlands \\ ${ }^{4}$ Department of Molecular and Cellular Neurobiology, Center for Neurogenomics and Cognitive Research, \\ Neuroscience Amsterdam, Vrije Universiteit Amsterdam, Amsterdam, The Netherlands \\ ${ }^{5}$ Research and Development, Pluryn, Nijmegen, The Netherlands \\ ${ }^{6}$ Psychology Department, The REACH Institute, Arizona, United States of America \\ ${ }^{7}$ Trimbos Institute, Utrecht, The Netherlands \\ ${ }^{8}$ EMGO Institute for Health and Care Research, VU University Medical Center, Amsterdam, The Netherlands
}

\begin{abstract}
Twin studies have shown substantial heritability for polysubstance use. Previous research has sought to pinpoint this genetic influence to variants in genes related to dopamine signaling, that are known to lower baseline dopamine levels (hypodopaminergic function). Candidategene studies often used single-gene designs and have yielded inconsistent results. Genome-wide association studies mainly include Single Nucleotide Polymorphisms (SNPs). In this study, a risk score was calculated based on both SNPs as well as Variable Number of Tandem Repeats (VNTRs).
\end{abstract}

Survey data on nicotine, alcohol and cannabis use from two family samples were analysed $(\mathrm{N}=2435$ and $\mathrm{N}=1173)$. Moderate and problematic polysubstance uses were explored. A polygenic risk score was calculated by averaging the number of hypodopaminergic variants in three polymorphisms. Polysubstance use was regressed on this score with sex and age as covariates. Power was sufficient to detect small effect sizes $\left(R^{2}=0.4-0.8 \%\right)$.

The hypodopaminergic polygenic risk score (HPRS) was not related to polysubstance use in either sample. There were some indications for opposing effects of individual polymorphisms and separate substance use outcomes and for an interaction of the polygenic risk score with education level. There were no effects of a score extended with extra polymorphisms, and there were no quadratic effects of the HPRS.

The HPRS did not predict polysubstance use. Several explanations for these findings were ruled out. Future research might employ more comprehensive genetic models, thereby including geneenvironment interaction.

Keywords: Dopamine, Substance use, Polygenic risk scores, Reward deficiency, Gene-environment interaction.

Accepted on June 21, 2017

\section{Introduction}

In the Netherlands, about $25 \%$ of the population older than twelve is a current smoker, $77 \%$ is a current alcohol drinker, and $20 \%$ has used cannabis at least once [1], which is largely in line with prevalence estimates from developed countries worldwide [2-4]. Factors that influence whether an individual (ab)uses a substance have been found to be shared across different substances and across moderate and problematic use patterns [5].

Genetic predisposition may be such a shared vulnerability 
factor. Twin models show that the genetic factors underlying nicotine, alcohol, and cannabis use overlap to a large extent [6]. Molecular genetic studies show that variants associated with the use of one substance also show a relation with the use of other substances, at least when looking at the same stage of use. For example, there are substantial genetic correlations between smoking initiation and cannabis initiation and between glasses of alcohol per week and number of cigarettes per day [7]. Likewise, genetic risk factors for smoking quantity predicted drinking quantity [8]. Therefore, it is sensible to look at multiple substances concurrently when considering the etiology of substance use.

\section{Dopamine-mediated vulnerability to substance use}

Traditional candidate-gene studies have sought to pinpoint the genetic influence in substance use at dopamine-related genes. These genes are considered plausible candidates, because of the function of dopamine in the brain's reward system. Addictive substances enhance levels of dopamine, resulting in feelings of pleasure $[9,10]$. According to the reward deficiency hypothesis some individuals are more prone to substance use than others because of differences in dopamine function. It has been proposed that individuals with lower baseline dopamine levels are more easily 'bored' and will seek more stimulation in order to experience the rewarding effects of dopamine [11,12]. Indeed, results from PET studies suggest lower dopamine receptor availability, receptor binding, and release in substance abusers than in controls [13].

These lower homeostatic dopamine levels may be caused by variations in dopamine-related genes. For example, alleles related to deficient dopamine reception (such as TaqI A1 in DRD2) might lead to lower basal dopamine ('hypodopaminergic) function and thus to lower reward sensitivity, which might then elicit substance-seeking behavior [14]. Many similar hypodopaminergic polymorphisms have been implicated in substance use. Importantly, a large proportion of those polymorphisms are not Single Nucleotide Polymorphisms (SNPs) but Variable Number of Tandem Repeats (VNTRs). Whereas a SNP is a variation of only one nucleotide, VNTRs are variations in the length of a repeat sequence of larger units of DNA. Genome-Wide Association
Studies (GWAS), which look for an association between genetic variation and a given phenotype, have as of yet not included VNTRs.

\section{Hypodopaminergic polygenic risk score}

As a reflection of dopamine-related genetic vulnerability to substance use, this study will use a genetic risk score for hypodopaminergic functioning. Variations in dopaminerelated genes may lead to individual differences in basal dopamine levels, for example by influencing the number of dopamine receptors. These genes all have a small contribution, so considering them together is a more powerful method for identifying genetic risk than a single-gene approach. Although other recent studies have used polygenic risk scores in predicting substance use [8], these generally did not include non-SNP variations.

To the best of our knowledge, only two studies have used a sum score of risk alleles for substance use combining both SNPs and VNTRs. One study looked at the number of alleles associated with hypodopaminergic function and found this number to be associated with the use of licit and illicit substances in adolescent males [15]. In contrast, Davis and Loxton [16] used a score of similar variants, but found that alleles associated with higher dopamine levels predicted behavioral and substance addiction. These conflicting results might be due to differences in outcome, the exact polymorphisms under study and importantly, in the choice for which allele of each variant was considered as the risk allele.

For the current study, the literature was therefore carefully examined in order to make an informed prediction. Well-studied polymorphisms with a clear implication in dopamine function and substance use were included. Many studies showing a relation between these polymorphisms and substance use could be identified, of which representative examples are given in Table 1. However, conflicting studies were identified as well (Table 1), underlining the need for more powerful tests of those associations. Most studies identified alleles associated with low dopamine function as conferring risk for substance use, which is in line with the reward deficiency hypothesis. Thus, for the current study, we counted the number of alleles associated with low dopamine

Table 1. Overview of polymorphisms in dopamine-related genes included in the hypodopaminergic polygenic risk score.

\begin{tabular}{|c|c|c|c|c|c|}
\hline \multirow{2}{*}{ Gene } & \multirow{2}{*}{ Polymorphism } & \multirow{2}{*}{ Risk allele } & \multirow{2}{*}{$\begin{array}{l}\text { Dopamine-related } \\
\text { effect of risk allele }\end{array}$} & \multicolumn{2}{|c|}{ Representative literature examples } \\
\hline & & & & Supportive & Opposing \\
\hline $\begin{array}{c}\text { DAT1 } \\
\text { dopamine transporter gene }\end{array}$ & $\begin{array}{l}\text { 3' UTR 40-bp } \\
\text { VNTR }\end{array}$ & $10 \mathrm{R}$ & Enhanced clearance & $\begin{array}{c}\text { Smoking: Laucht et al. [52]; Herman } \\
\text { et al. [53]. } \\
\text { Alcohol: Schacht et al. [54] } \\
\text { Drugs: Stolf et al. [55] }\end{array}$ & $\begin{array}{l}\text { Smoking: Munafo et al. [56] } \\
\text { Substance abuse: Blum et al. [14] } \\
\text { Polydrug use: Conner et al. [15] }\end{array}$ \\
\hline $\begin{array}{c}\text { DRD2 } \\
\text { dopamine receptor D2 gene }\end{array}$ & $\begin{array}{l}\text { rs1800497 TaqlA } \\
\text { SNPa }^{a}\end{array}$ & $\mathrm{~T}$ & $\begin{array}{c}\text { Reduced D2 receptor } \\
\text { density }\end{array}$ & $\begin{array}{l}\text { Smoking: Munafo, et al. [57] } \\
\text { Alcohol: Smith et al. [58] } \\
\text { Drugs: Esposito-Smythers et al. [59] }\end{array}$ & Alcohol: Hallikainen et al. [60] \\
\hline $\begin{array}{c}\text { DRD4 } \\
\text { dopamine receptor D4 gene }\end{array}$ & $\begin{array}{l}3^{\text {rd }} \text { exon } 48-b p \\
\text { VNTR }\end{array}$ & $\begin{array}{l}\text { long }(>=7 \\
\text { repeats) }\end{array}$ & $\begin{array}{l}\text { Reduced receptor } \\
\text { efficiency }\end{array}$ & $\begin{array}{c}\text { Addiction: McGeary [61] } \\
\text { Substance use: Olsson et al. [62] }\end{array}$ & Addiction: Comings et al. [63] \\
\hline
\end{tabular}

A supportive research finding indicates that a positive relation was found between the risk allele and substance use; an opposing finding indicates a positive relation between the non-risk allele and substance use

aThis polymorphism was previously thought to lie in the DRD2 gene but is actually located in the ankyrin repeat and kinase domain containing 1 (ANKK1) gene next to DRD2 
for our genetic risk score. Although the number of selected polymorphisms is limited, previous polygenic risk score studies have successfully predicted phenotypes using a score of only a few variants [17-21]. Because heritability is likely to be overlapping for different substances, and because it appears from the literature that the same variants are implied, it is hypothesized that reward-related polymorphisms form a liability factor common to different substance use phenotypes. Thus, we predict that hypodopaminergic genetic risk predicts higher chances of having initiated use of multiple substances.

\section{Materials and Methods}

To test whether hypodopaminergic polygenic risk would predict polysubstance use, data of two independent family samples were utilized.

\section{NTR sample}

Participants: The first sample included participants from the Netherlands Twin Register (NTR), an ongoing longitudinal study of twins and their family members. A detailed description of study methods has been provided elsewhere [22]. Data on substance use were collected between 1991 and 2014 in nine waves. For a subsample there were also data on SNPs and VNTRs (Figure 1). Because of the family structure in the sample, age had a bimodal distribution, with a mean of $\mathrm{M}=22.1(\mathrm{SD}=3.0, \mathrm{~N}=1139)$ and $\mathrm{M}=47.1(\mathrm{SD}=11.2$, $\mathrm{N}=1296$ ). Females made up $62.8 \%$ of the sample.

Genotype data: NTR participants have been genotyped for common SNPs and VNTRs using procedures described

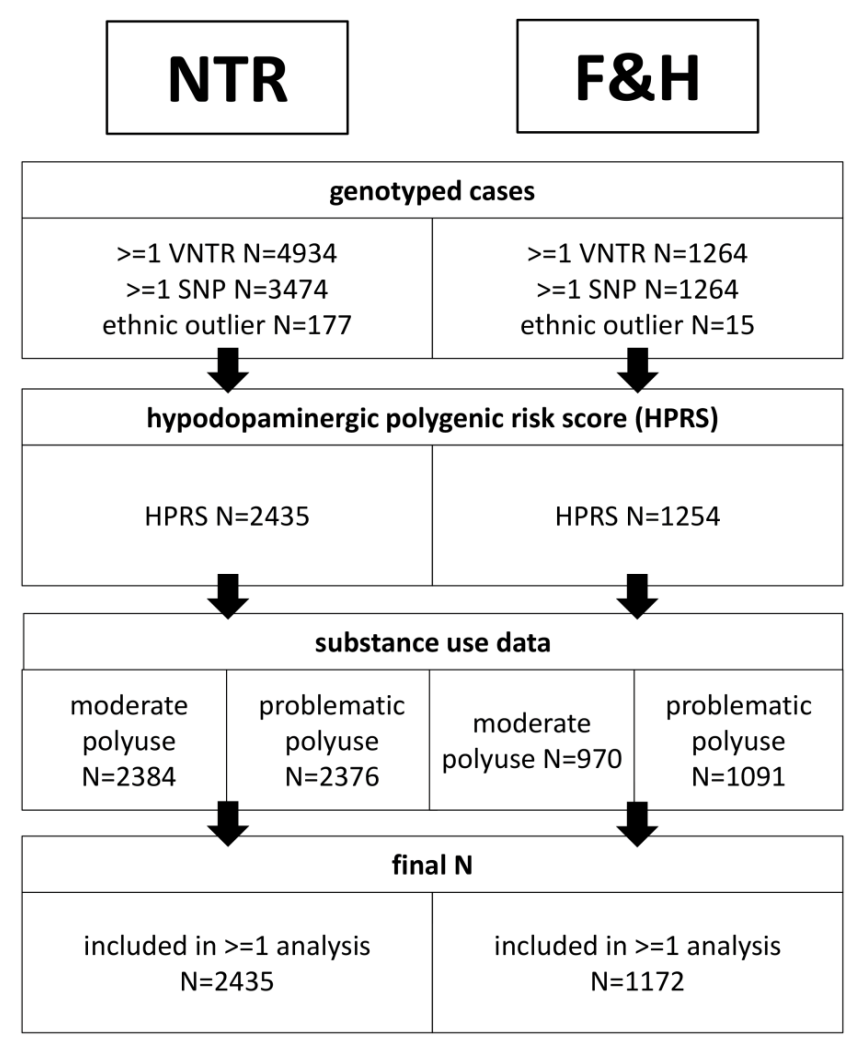

Figure 1. Data availability. Flowchart of data availability in the NTR (left) and F\&H sample (right). elsewhere [22,23]. The hypodopaminergic polygenic risk score (HPRS) was the average number of risk alleles in the three variants. Individuals with more than one missing genotype were excluded $(\mathrm{N}=58)$. The formula for this procedure was:

$$
H P R S=\frac{\sum\left(D A T 1_{10 R}, D R D 2_{T}, D R D 4_{\text {long }}\right)}{N_{v}}
$$

where, the numerator counts the risk alleles $(0,1$ or 2 per genetic variant) and the denominator $N_{v}$ is the number of genotyped variants (minimal two). Thus, the HPRS reflects the mean number of risk alleles for each individual. The variants were not weighted by previously found effect sizes (as is common for polygenic risks score studies), since GWAS on which such weighting procedures are based have not included VNTRs. Principal components for genetic ancestry were not used to control for population stratification, as required data were not available for all NTR participants and no such data were available in the F\&H sample. NonCaucasian individuals were excluded from analysis $(\mathrm{N}=177)$ and individuals with no information on ethnicity $(\mathrm{N}=663)$ were kept in the analyses (results did not change when they were excluded; data not shown). The data met quality criteria for minor allele frequency (MAF>0.05), Hardy-Weinberg disequilibrium $(\mathrm{H}-\mathrm{W}$, threshold $\mathrm{p}>0.001)$ and Mendelian errors $(<0.02$ per variant).

\section{F\&H sample}

Participants: The second sample included participants from the Dutch longitudinal Family and Health (F\&H) study. Details on the F\&H sample and procedures are provided elsewhere [24,25]. The sample consisted of families of two children and both their parents ( $\mathrm{N}=428$ families). Survey data were collected between 2002 and 2009 in six yearly waves. DNA was collected for 1265 individuals between 2006 and 2007 via saliva sampling (Figure 1).

Mean age was $19.0(\mathrm{SD}=0.8)$ years for the child cohort $(\mathrm{N}=621)$ and $49.8(\mathrm{SD}=3.7)$ years for the parent cohort $(\mathrm{N}=551)$. About half of the sample was female $(49.4 \%)$.

Genotype data: Individual variants were genotyped using polymerase chain reaction [26]. The HPRS again comprised the mean number of risk alleles in the DAT1,DRD4 and DRD2 genes. Individuals born outside of Europe were excluded $(\mathrm{N}=15)$. Persons with missing birth country were included $(\mathrm{N}=61$; results did not change when these individuals were not considered; data not shown). The genotype variables withstood MAF ( $>0.05)$ and Hardy-Weinberg quality control $(\mathrm{p}>0.001)$.

\section{Measures}

\section{Moderate substance use}

Similar survey items were used to determine moderate substance use in both samples. Moderate polysubstance use was defined as having done at least two of the following: 1) smoked daily; 2) drank at least one glass of alcohol per day; 3 ) ever used cannabis (Table 2). In the F\&H sample, cannabis 
Citation: Pasman JA, Verweij KJH, Treur JL, et al. Hypodopaminergic polygenic risk for polysubstance use. J Psychol Cognition. 2017;2(2): 138-148.

Table 2. Overview of aggregate measures included in the main and exploratory analyses, with corresponding cut-off points (if applicable) and descriptive statistics.

\begin{tabular}{|c|c|c|c|c|}
\hline \multirow[b]{2}{*}{ Composites } & \multicolumn{2}{|l|}{ NTR } & \multicolumn{2}{|l|}{ F\&H } \\
\hline & Based on measures & Descriptive & Based on measures & Descriptive \\
\hline $\begin{array}{l}\text { HPRS } \\
\text { mean number of risk } \\
\text { alleles }\end{array}$ & DAT1, DRD4, DRD2 & $\begin{array}{l}N=2435 \\
M=0.81 \\
S D=0.38\end{array}$ & DAT1, DRD4, DRD2 & $\begin{array}{l}N=1172 \\
M=0.76 \\
S D=0.34\end{array}$ \\
\hline $\begin{array}{c}\text { eHPRS }^{\mathbf{b}} \\
\text { mean number of risk } \\
\text { alleles }\end{array}$ & $\begin{array}{l}\text { DAT1, DRD4, DRD2, DRD5, MAOA, } \\
\text { OPRM1, COMT }\end{array}$ & $\begin{array}{l}N=1771 \\
M=1.01 \\
S D=0.24\end{array}$ & DAT1, DRD4, DRD2, OPRM1 & $\begin{array}{l}N=1122 \\
M=1.02 \\
S D=0.27\end{array}$ \\
\hline $\begin{array}{l}\text { Moderate poly use } \\
\text { At least two substances } \\
\text { used over time }\end{array}$ & $\begin{array}{l}>=1 \text { cigarette per day } \\
\text { >=6 glasses alcohol per week \& } \\
\text { >=drinking a few times per week } \\
\text { ever use of cannabis }\end{array}$ & $\begin{array}{l}\mathrm{N}=2384 \\
\text { prevalence }=37.2 \%\end{array}$ & $\begin{array}{l}>=1 \text { cigarette per day } \\
>=6 \text { glasses alcohol per week \& } \\
\text { >=drinking a few times per week } \\
\text { ever use of cannabis (for adolescents } \\
\text { only) }\end{array}$ & $\begin{array}{l}\mathrm{N}=970 \\
\text { Prevalence }=62.6 \%\end{array}$ \\
\hline $\begin{array}{l}\text { Problematic poly use } \\
\text { Problematic use of at } \\
\text { least two substances } \\
\text { over time }\end{array}$ & $\begin{array}{l}\text { FTND }^{\text {a }} \text { score of }>=6 \\
\text { CAGE score of }>=2 \\
\text { regular cannabis use }\end{array}$ & $\begin{array}{l}\mathrm{N}=2376 \\
\text { prevalence }=2.4 \%\end{array}$ & $\begin{array}{l}\text { FTND score of }>=6 \\
\text { RAPI score of }>=8 \\
\text { regular cannabis use (for } \\
\text { adolescents only) }\end{array}$ & $\begin{array}{l}\mathrm{N}=1091 \\
\text { Prevalence }=4.3 \%\end{array}$ \\
\hline
\end{tabular}

${ }^{\mathrm{a} F T N D}=$ Fagerström Test of Nicotine Dependence; $\mathrm{CAGE}=$ alcohol problems questionnaire; RAPI=Rutgers Alcohol Problem Index

${ }^{b}$ Explained in the exploratory analyses

'Following definitions from Centraal Bureau voor de Statistiek [1]

${ }^{\mathrm{d}}$ Following guidelines from Gezondheidsraad [64]. Drinking at least one glass per day corresponded to the answering category of drinking at least 6-10 glasses per week combined with drinking at least a few times per week

use was only measured in adolescents. No distinction was made between using substances concurrently or at different time points, so that an ex-smoker who currently drank alcohol was in the same category as someone who both drank and smoked currently. We expect that using such a composite will enhance power to detect effects, as it measures initiation of use of multiple substances, and will serve the purpose of capturing genetic variance common to different substance use phenotypes.

\section{Problematic substance use}

For smoking, in both samples the Fagerström Test of Nicotine Dependence (FTND) was used. The 6-item FTND measures the degree of nicotine dependence [27]. The Dutch version of this questionnaire has shown sufficient reliability and validity [28].

For drinking, the 4-item CAGE questionnaire was used in the NTR sample, and the short version of the Rutgers Alcohol Problems Index (RAPI) was used in the F\&H sample. CAGE is an acronym for the four items in the questionnaire: feeling you need to cut down on drinking; feeling annoyed by people criticizing your drinking; feeling Guilty about drinking; and using alcohol as an Eye-opener to wake up in the morning [29]. The Dutch version has shown sufficient quality [30]. The common cut-off score of 2 has shown to yield good specificity and sensitivity [31]. The RAPI is a longer instrument aimed at measuring problematic use, and includes items similar to the CAGE, such as 'was told by a friend, neighbor or relative to stop or cut down drinking' [32]. The shortened 18-item version correlates highly with the original version, which has good measurement properties [33]. Previous studies used a cut-off total score of $>=15$ for the 23-item version to classify persons as problematic users [34-36], which corresponds to a $>=12$ cut-off for the 18 -item version. Although they are different instruments, the RAPI and CAGE show overlap [37].

In both samples problematic cannabis use was determined based on a question of the format 'Have you ever started using cannabis on a regular basis?' In the F\&H sample, this information was only available for adolescents. A person was considered a problematic polysubstance user when he/she had met at least two of the following criteria on at least one measurement moment: 1) score above cut-off for the FTND; 2) score above cut-off for the CAGE/ RAPI; 3) regular use of cannabis.

\section{Statistical analyses}

A logistic generalized estimating equations (GEE) model was used to examine the relationship between the hypodopaminergic polygenic risk score and polysubstance use. GEE is a form of multilevel regression with the possibility to control for (family) clustering. Separate analyses were conducted for both outcome measures and for both samples. Age and sex were included as covariates in the analyses. Birth cohort (being a parent or a child in the family) correlated almost perfectly with age and was not included in the model. Continuous variables were centered on the sample mean.

\section{Power}

In Figure 2 power calculations are depicted for both samples. Effect sizes of individual genetic variants are commonly found to be between $\mathrm{R}^{2}=0.1$ to $1 \%[38,39]$. In the current investigation, an $\mathrm{R}^{2}$ of $0.3-3 \%$ might thus be expected, 


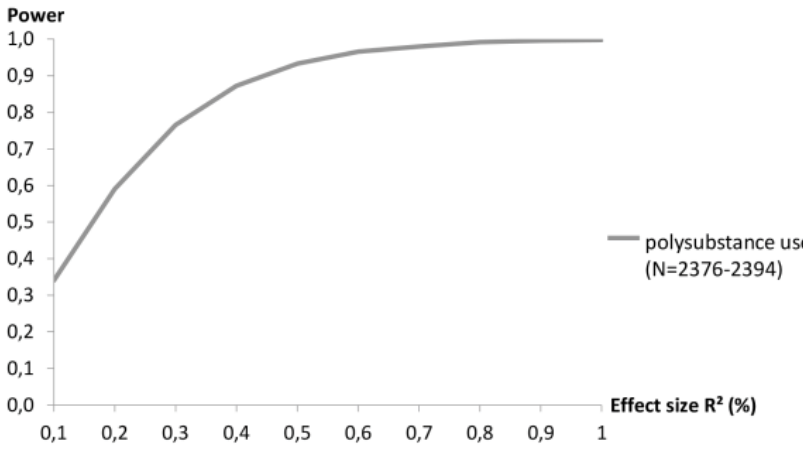

(a)

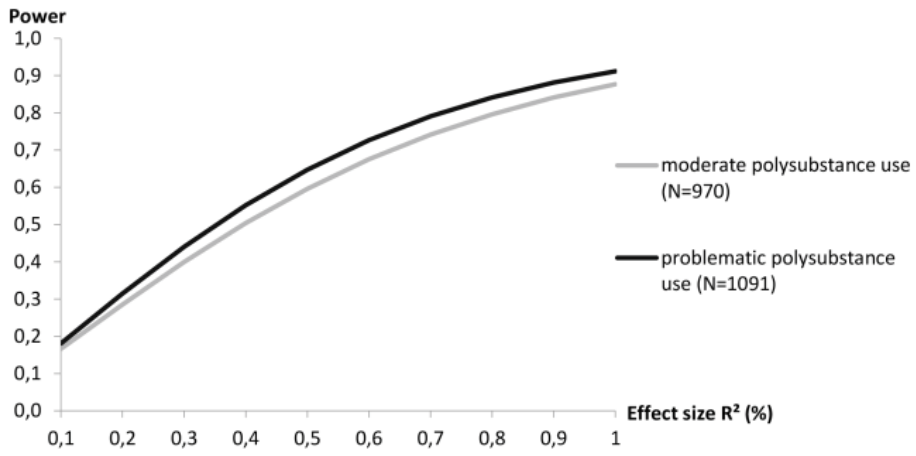

(b)

Figure 2. Power analysis. Power for main analysis in NTR (panel a) and F\&H sample (panel b). In the NTR sample, sample sizes for both outcomes were very similar, so that power was estimated for both outcomes together. Estimations of effect sizes are in percentage of explained variance $\left(R^{2}\right)$. An $\alpha$-level of 0.05 was used.

since three variants were considered. As can be seen in Figure 2, power in the NTR sample is sufficient $(80 \%)$ for an explained variance of approximately $0.4 \%$ or more. In the F\&H sample, a larger effect size of $0.8 \%$ would be required to have an $80 \%$ chance of detecting the effect.

\section{Results}

Descriptive statistics for the predictor and outcome variables were given in Table 2 . The HPRSs were normally distributed between 0 and 2 with a mean of 0.81 and 0.76 , suggesting that the risk alleles were somewhat rarer than the non-risk alleles. In the NTR, $36 \%$ had ever smoked on a daily basis, $55 \%$ had drunk regularly, and $28 \%$ had used cannabis. In the $\mathrm{F} \& \mathrm{H}$, these rates were $49 \%, 83 \%$ and $41 \%$ (for adolescents only), respectively. Using one substance on a moderate level predicted the use of another substance on a moderate level $\left(\chi^{2}=111.9, \mathrm{p}<0.01\right.$ for NTR; $\chi^{2}=16.6$, $\mathrm{p}<0.01$ for $\mathrm{F} \& \mathrm{H})$. Likewise, the problematic substance use phenotypes were significantly related $\left(\chi^{2}=29.1, p<0.01\right.$ for NTR; $\chi^{2}=43.0, p<0.01$ for $\mathrm{F} \& \mathrm{H}$ ), justifying the aggregation in the polysubstance use indices.

\section{Main effects}

There was no relationship between the HPRS and moderate or problematic polysubstance use in either sample (Table 3). In all models, there was a main effect of sex, such that males were more likely than females to show moderate and problematic polysubstance use. Results did not change when analyses were conducted separately for males and females or for young and old cohorts, or when the interactions with these factors were included in the analyses (data not shown). Effects of age were significant in some models, but the coefficients were small and in opposing directions for the samples.

\section{Exploratory analyses}

Below, possible explanations for the initial null findings are examined. Because of the post hoc nature of these tests, which increases the multiple testing burdens, a stricter $\alpha$-level of 0.01 was adopted for the exploratory analyses.

\section{Extended risk score}

As a possible explanation, it was investigated whether a more extensive measure of hypodopaminergic risk could predict polysubstance use. The HPRS was extended (eHPRS) using risk alleles in other available polymorphisms that have shown a relation with hypodopaminergic function and substance use (Table 4). Four additional polymorphisms (in the genes DRD5, OPRM1, COMT, MAOA) were selected in the NTR, and one (in OPRM1 gene) in the F\&H sample. The eHPRS was calculated if data for at least five (in the NTR sample) or four polymorphisms (in the F\&H sample) were available. Results showed no effect of the eHPRS on either outcome (Supplementary Table S1).

\section{Gene-environment interaction}

Possibly, the effect of the HPRS was obscured by an interaction with environmental influences. If genetic risk would lead to more polysubstance use in one environmental group, but to lower polysubstance use in another, the main effect would not be found in the combined group. One plausible environmental variable is socioeconomic status, of

Table 3. Results for main analyses using the core hypodopaminergic polygenic risk score.

\begin{tabular}{|c|c|c|c|c|c|}
\hline & \multirow[b]{2}{*}{ Predictor } & \multicolumn{2}{|c|}{ Moderate poly-substance use } & \multicolumn{2}{|c|}{ Problematic poly-substance use } \\
\hline & & b (SD) & $\mathbf{p}$ & b (SD) & $\mathbf{p}$ \\
\hline \multirow{3}{*}{$\begin{array}{c}\text { NTR } \\
\mathrm{N}=2384 \text { (moderate) } \\
\mathrm{N}=2376 \text { (problematic) }\end{array}$} & HPRS & $0.02(0.13)$ & 0.91 & $-0.02(0.43)$ & 0.96 \\
\hline & age & $-0.02(0.00)$ & $<0.01^{* *}$ & $-0.01(0.01)$ & 0.30 \\
\hline & sex & $-0.50(0.09)$ & $<0.01^{* *}$ & $-0.71(0.28)$ & $0.01^{*}$ \\
\hline \multirow{2}{*}{$\begin{array}{c}\text { F\&H } \\
\mathrm{N}=970 \text { (moderate) } \\
\mathrm{N}=1091 \text { (problematic) }\end{array}$} & HPRS & $-0.19(0.22)$ & 0.39 & $-0.18(0.48)$ & 0.71 \\
\hline & age & $0.05(0.01)$ & $<0.01^{\star *}$ & $-0.04(0.01)$ & $<0.01^{* \star}$ \\
\hline
\end{tabular}

*significant at $\alpha=0.05 * *$ significant at $\alpha=0.01$ 
Citation: Pasman JA, Verweij KJH, Treur JL, et al. Hypodopaminergic polygenic risk for polysubstance use. J Psychol Cognition. 2017;2(2): 138-148.

Table 4. Summary of polymorphisms in more peripherally dopamine-related genes that were included in the explorative hypodopaminergic polygenic risk score (eHPRS).

\begin{tabular}{|c|c|c|c|c|c|}
\hline \multirow{2}{*}{ Gene } & \multirow{2}{*}{ Polymorphism } & \multirow{2}{*}{ Risk allele } & \multirow{2}{*}{$\begin{array}{l}\text { Dopamine-related } \\
\text { effect of risk allele }\end{array}$} & \multicolumn{2}{|c|}{ Research findings $^{b}$} \\
\hline & & & & Supportive & Opposing \\
\hline $\begin{array}{l}\text { DRD5 } \\
\text { Dopamine } \\
\text { receptor d5 gene }\end{array}$ & $\begin{array}{l}\text { 5'-di-nucleotide } \\
\text { repeat VNTR }\end{array}$ & $148 \mathrm{bp}$ & Non-functionala & $\begin{array}{c}\text { Smoking: Sullivan et al. [65] } \\
\text { Substance dependence: Vanyukov et } \\
\text { al. [66] }\end{array}$ & \\
\hline $\begin{array}{l}\text { OPRM1 } \\
\mu \text {-opioid receptor } \\
\text { gene }\end{array}$ & $\begin{array}{c}\text { rs1799971 A118G } \\
\text { SNP }\end{array}$ & G & Reduced release & $\begin{array}{l}\text { Smoking: Kleinjan et al. [67] } \\
\text { Alcohol: Miranda et al. [68] } \\
\text { Drug dependence: Zhang et al. [69] }\end{array}$ & $\begin{array}{c}\text { Alcoholism: Du and Wan [70] } \\
\text { Alcoholism and polysubstance abuse: Schinka } \\
\text { et al. [71] }\end{array}$ \\
\hline $\begin{array}{l}\text { COMT } \\
\text { Catechol-O- } \\
\text { methyltrans- } \\
\text { ferase gene }\end{array}$ & $\begin{array}{c}\mathrm{rs} 4680 \\
\mathrm{Val}^{158} \mathrm{Met}^{\mathrm{b}} \mathrm{SNP}\end{array}$ & $\mathrm{G}(\mathrm{Val})$ & $\begin{array}{l}\text { Increased } \\
\text { catabolism }\end{array}$ & $\begin{array}{l}\text { Smoking: Munafo et al. [56] } \\
\text { Alcoholism: Enoch et al. [72] } \\
\text { Cannabis: Isir et al. [73] }\end{array}$ & $\begin{array}{c}\text { Smoking: Beuten et al. [74] } \\
\text { Alcohol: Hendershot et al. [75] } \\
\text { Cannabis: Verdejo-García et al. [76] }\end{array}$ \\
\hline $\begin{array}{c}\text { MAOA } \\
\text { Monoamine } \\
\text { oxidase-A gene }\end{array}$ & $\begin{array}{c}\text { promoter } 30 \mathrm{bp} \\
\text { VNTR }^{\mathrm{a}}\end{array}$ & $\begin{array}{c}\text { long }(>=3.5 \\
\text { repeats })\end{array}$ & $\begin{array}{l}\text { Increased } \\
\text { catabolism }\end{array}$ & $\begin{array}{l}\text { Smoking: Wiesbeck et al. [77] } \\
\text { Alcohol: Nilsson et al. [78] } \\
\text { Drug abuse: Gade et al. [79] }\end{array}$ & $\begin{array}{c}\text { Smoking: Jin et al. [80] } \\
\text { Alcohol: Samochowiec et al. [81] } \\
\text { Substance use disorders: Vanyukov et al. [82] }\end{array}$ \\
\hline
\end{tabular}

${ }^{a}$ The DRD5 polymorphism is likely to be in linkage disequilibrium with variants that decrease dopamine receptor 1 efficiency

${ }^{\mathrm{b}} \mathrm{A}$ positive research finding indicates that a positive relation was found between the risk allele and substance use; an opposing finding indicates a positive relation between the non-risk allele and substance use

'Non-European ancestry study sample (i.e., Asian, Indian-American)

Table 5. Results for main analyses using the core hypodopaminergic polygenic risk score including the main and interaction effect of family education level.

\begin{tabular}{|c|c|c|c|c|c|}
\hline & \multirow[b]{2}{*}{ Predictor } & \multicolumn{2}{|c|}{ Moderate poly-substance use } & \multicolumn{2}{|c|}{ Problematic poly-Substance use } \\
\hline & & b (SD) & $\mathbf{p}$ & b (SD) & $\mathbf{p}$ \\
\hline \multirow{5}{*}{$\begin{array}{c}\text { NTR } \\
\mathrm{N}=2315 \text { (moderate) } \\
\mathrm{N}=2312 \text { (problematic) }\end{array}$} & HPRS & $-0.05(0.40)$ & 0.81 & $-0.19(1.23)$ & 0.85 \\
\hline & Age & $-0.02(0.00)$ & $<0.01^{* *}$ & $-0.01(0.01)$ & 0.32 \\
\hline & Sex & $-0.52(0.09)$ & $<0.01^{* *}$ & $-0.71(0.29)$ & $0.02^{*}$ \\
\hline & Education & $-0.16(0.10)$ & 0.10 & $-0.49(0.30)$ & 0.11 \\
\hline & HPRS*education & $0.06(0.25)$ & 0.81 & $0.15(0.78)$ & 0.85 \\
\hline \multirow{5}{*}{$\begin{array}{c}\mathbf{F} \& \mathbf{H} \\
\mathrm{N}=969 \text { (moderate) } \\
\mathrm{N}=1090 \text { (problematic) }\end{array}$} & HPRS & $-1.88(0.80)$ & $0.02^{*}$ & $-2.81(1.49)$ & 0.06 \\
\hline & Age & $0.05(0.01)$ & $<0.01^{* *}$ & $-0.04(0.01)$ & $<0.01$ \\
\hline & Sex & $0.58(0.13)$ & $<0.01^{* *}$ & $1.49(0.36)$ & $<0.01^{* *}$ \\
\hline & Education & $-0.16(0.17)$ & 0.33 & $-0.33(0.36)$ & 0.35 \\
\hline & HPRS*education & $1.05(0.47)$ & $0.03^{*}$ & $1.73(0.91)$ & 0.06 \\
\hline
\end{tabular}

*significant at $\alpha=0.05 * *$ significant at $\alpha=0.01$

which education level is an important element. For example, it has been found that individuals with a higher education level have a lower risk for alcohol problems, so that they will not develop those unless they have a high genetic liability, whereas environmental risk is more important for individuals with a low education level [40]. In both the NTR and F\&H sample, information on education level was available. For individuals under age 25, who may not have finished their education, parental education was used as a proxy for socioeconomic status. Education level was dichotomized using cut-offs as described in Table 2. The interaction of education level with the HPRS was explored.

Results of these analyses are summarized in Table 5. In the NTR sample, no significant main or interaction effects for education were observed. In the $\mathrm{F} \& \mathrm{H}$, there was a trend for an interaction effect $(p=0.03)$, such that a higher HPRS predicted less substance use, but only for persons with a low education level.

\section{Relation between HPRS and separate substances}

Possibly, the risk score shows no association with an aggregate measure of polysubstance use, but does show an association with separate substance use types. If the association with separate substances would be in opposing directions, they would cancel each other out in the aggregate measure. To test this possibility, six GEE analyses were conducted for the substance use variables separately (moderate and problematic nicotine, alcohol, and cannabis use). No significant relations were found, although there was a trend in the NTR sample for moderate alcohol use in the direction opposite from what was expected $(\mathrm{p}=0.03)$ (Supplementary Table S2).

\section{Relation between polysubstance use and separate polymorphisms}

In the interaction model a negative effect was found of the HPRS on substance use. Therefore, it is possible that the risk alleles were not correctly selected based on the literature. To investigate this possibility, separate GEE analyses for each individual genetic variant were conducted. The results are summarized in Supplementary Tables S2 and S3. There were only two associations significant at the $\alpha=0.01$ level, both in the NTR sample, between $M A O A$ and moderate cannabis use and problematic alcohol use. There were as many variants with small positive as with small negative coefficients, so that these cancelled each other out in the sum score. Sample sizes for separate polymorphisms were smaller, so that these analyses may have been underpowered. 


\section{Quadratic effects}

Both positive and negative coefficients were found for separate polymorphisms and separate substance use outcomes. Possibly, low and high (rather than normal) dopamine functions are predictive of substance use. To test this possibility, the squared centered HPRS was added as a predictor in the model. This quadratic term was zero when a person had an average number of hyperdopaminergic risk alleles, and increased when he/she had a high or low number of alleles. Analyses using this quadratic term revealed no significant associations (Supplementary Table S4).

\section{Discussion}

This study aimed to test the association between three hypodopaminergic genetic variants and the use of multiple substances over life. In two samples, the hypodopaminergic polygenic risk score did not predict polysubstance use and this did not change when additional polymorphisms were included.

\section{Possible explanations}

Several explanations for the null results can be offered. First, although there was sufficient power to detect an effect of at least $\mathrm{R}^{2}=0.4-0.8 \%$, it could be that the true effect size was smaller than that. Also, power in the problematic polysubstance use analyses might have been compromised by the low prevalence of this phenotype.

As a second explanation, an interaction between genetic vulnerability and an environmental factor could have muddled the results. It has been suggested that interaction with environmental variables is one of the reasons why molecular genetics studies succeed in explaining only small part of the heritability estimates found in twin studies [41]. A plausible candidate for such an environmental variable is socioeconomic status, often indexed by (parental) education level. For example, it has been found that genetic factors are more important for people with a high education level than for those with a low education level in determining the risk for alcohol problems [40]. However, the null-results were not explained by an interaction with family education level, although there were some unexpected trends in the $\mathrm{F} \& \mathrm{H}$ dataset, showing a stronger negative relation between genetic risk and substance use for persons with a low education level.

Third, it might be that the genetic risk scores had opposing effects on the different substance use types, thus obscuring a main effect. This could be driven by one or more polymorphisms that have shown associations in opposing directions for different substances. As we tested this, however, the polygenic risk scores showed hardly any relations with the substance use variables separately, rendering this explanation insufficient.

As a fourth explanation, it was tested whether individual polymorphisms had opposing effects. Selection of hypodopaminergic alleles related to substance use was based on an extensive literature search, but reports were not consistent. Indeed, in both samples, the selected risk alleles showed both positive and negative relations with substance use phenotypes, suggesting that they canceled each other out in the combined scores. However, these individual effects were not significant. This is in line with many studies that did not find an effect of individual variants in dopamine-related genes on substance use [26,42-44], but in conflict with an even larger number of studies that did find an effect in the direction that was hypothesized or an effect in the opposing direction (Tables 1 and 4).

Finally, it was investigated if there was a quadratic effect of the risk score. This would mean that both hypo- and hyperdopaminergic alleles predict polysubstance use, in contrast to alleles related to normal dopaminergic function. Considering the opposing effects found for the candidate genes (Tables 1 and 4) this is a plausible explanation. Also, of the two studies to our knowledge that used a dopaminergic polygenic risk score similar to the one in the current investigation, one found an effect of hypodopaminergic alleles on substance use [15], but the other found a relation between a hyperdopaminergic alleles and addiction [16]. However, tests of a quadratic term in our study did not suggest that low and high numbers of hypodopaminergic alleles were predictive of polysubstance use as compared to average numbers of alleles.

Concluding, we could not sufficiently explain the nullresults with post hoc tests. This suggests that risk alleles in dopamine-related genes do not play a vital role in predicting polysubstance use. Indeed, large GWAS for substance use phenotypes [45-47] have rarely identified dopamine-related polymorphisms as their top results, suggesting that these may not be as important as has traditionally been assumed. This might mean that the relation with dopamine function is more indirect. For example, a variation in the CHRNA5 gene (rs16969968) related to smoking addiction reduces nicotine receptor activity, which may hamper the eventual dopamine response to nicotine [48]. Alternatively, the genetic etiology of substance use may lie more in other mechanisms than dopamine function, such as the metabolism of the substance. For example, there are indications that variants in the alcohol dehydrogenase $(\mathrm{ADH})$ gene cluster that are related to impaired alcohol metabolism lower the chances of alcohol dependence [49].

\section{Strengths and limitations}

This study aimed to tackle limitations of previous research. We used a design with polygenic risk scores and aggregate outcome measures in order to counteract power-problems associated with candidate-gene studies. Indeed, power was sufficient to detect reasonably small effect sizes. A second strength was that we replicated the analyses in a separate sample, which is paramount for genetic association studies [50]. Also, we included VNTRs, that have as of yet not been investigated in GWAS. Furthermore, the longitudinal nature of the data increased chances of reliably capturing substance use. Finally, we tested several explanations for our results, which give some indication for the reliability of our findings. 
An important limitation of this study lies in the identification of the genetic risk variants based on their proposed relation with hypodopaminergic function, although effects in other directions were explored. We restricted ourselves to genes for which a relation had been found, rather than genes that are in the same pathway but for which a clear effect on dopamine levels has not yet been revealed.

The use of an aggregated outcome measure might be viewed as a strength (as it should increase power to detect effects), but might also have introduced heterogeneity. Preliminary tests of the association among the separate substance use measures however suggested that aggregating them was sensible. Also, relations between the HPRS with separate substance use variables were explored and testing an aggregate measuring use of no versus 1 or more substance did not change results (not shown). The fact that only adolescent cannabis use was available in the $\mathrm{F} \& \mathrm{H}$ sample is unlikely to have biased the results, as the same results were obtained in the NTR sample, where adults were included in the measure. The measure of problematic cannabis use was based on one question measuring 'regular' use, which may not reliably capture problematic use. Still, it has been found that approximate measures of regular cannabis use (e.g. having used at least ten times) already predict later abuse and dependence [51].

\section{Conclusions and Future Directions}

We found a sum score of hypodopaminergic risk alleles to be unrelated to moderate and problematic polysubstance use. The most likely explanation for these findings seemed to be that these polymorphisms do not play a crucial role in substance use phenotypes. Future research might include (nonSNP) polymorphisms unrelated to dopamine, or might adopt a hypothesis-free approach to circumvent the difficulty with defining risk alleles. Also, studies should include a role for gene-environment interaction, as there were indications that this may alter results. Time may be right for more complex genomewide models, where interaction, mediation, gene-environment correlation, and opposing effects are included to disentangle the relation between dopamine-related genes and substance use.

\section{References}

1. Centraal Bureau voor de Statistiek. Leefstijl en (preventief) gezondheidsonderzoek: Persoonskenmerken. 2016.

2. World Health Organization. Global status report on alcohol and health. 2014.

3. World Health Organization. The health and social effects of nonmedical cannabis use. 2016.

4. World Health Organization. Prevalence of tobacco smoking. 2016.

5. Palmer RH, Young SE, Hopfer CJ, et al. Developmental epidemiology of drug use and abuse in adolescence and young adulthood: Evidence of generalized risk. Drug Alcohol Depend. 2009;102(1-3):78-87.
6. Young SE, Rhee SH, Stallings MC, et al. Genetic and environmental vulnerabilities underlying adolescent substance use and problem use: General or specific? Behav Genet. 2006;36(4):603-15.

7. Nivard M, Verweij K, Minică C, et al. Connecting the dots, genome-wide association studies in substance use. Mol Psychiatry. 2016;21:733-5.

8. Vink JM, Hottenga JJ, de Geus EJ, et al. Polygenic risk scores for smoking: Predictors for alcohol and cannabis use? Addiction. 2014;109(7):1141-51.

9. Di Chiara G, Imperato A. Drugs abused by humans preferentially increase synaptic dopamine concentrations in the mesolimbic system of freely moving rats. Proc Natl Acad Sci. 1988;85:5.

10. Tanda G, Pontieri FE, Di Chiara G. Cannabinoid and heroin activation of mesolimbic dopamine transmission by a common $\mu 1$ opioid receptor mechanism. Science. 1997;276(5321):2048-50.

11. Blum K, Cull JG, Braverman ER, et al. Reward deficiency syndrome. Am Sci. 1996;84(2):132-45.

12. Bowirrat A, Oscar-Berman M. Relationship between dopaminergic neurotransmission, alcoholism and reward deficiency syndrome. Am J Med Genet. 2005;132B(1):2937.

13. Hommer DW, Bjork JM, Gilman JM. Imaging brain response to reward in addictive disorders. Ann N Y Acad Sci. 2011;1216(1):50-61.

14. Blum K, Oscar-Berman M, Barh D, et al. Dopamine genetics and function in food and substance abuse. J Genet Syndr Gene Ther. 2013;4(121).

15. Conner BT, Hellemann GS, Ritchie TL, et al. Genetic, personality, and environmental predictors of drug use in adolescents. J Subst Abuse Treat. 2010;38(2):178-90.

16. Davis C, Loxton NJ. Addictive behaviors and addictionprone personality traits: Associations with a dopamine multilocus genetic profile. Addictive Behaviors. 2013;38(7):2306-12.

17. Belsky DW, Moffitt TE, Baker TB, et al. Polygenic risk and the developmental progression to heavy, persistent smoking and nicotine dependence: Evidence from a 4-decade longitudinal study. JAMA Psychiatry. 2013;70(5):534-42.

18. Brody GH, Chen YF, Beach SR. Differential susceptibility to prevention: GABAergic, dopaminergic, and multilocus effects. J Child Psychol Psychiatry. 2013;54(8):863-71.

19. David SP, Strong DR, Leventhal AM, et al. Influence of a dopamine pathway additive genetic efficacy score on smoking cessation: Results from two randomized clinical trials of bupropion. Addiction. 2013;108(12):2202-11.

20. Davis C, Loxton NJ, Levitan RD, et al. 'Food addiction' and its association with a dopaminergic multilocus genetic profile. Physiol Behav. 2013;118:63-9. 
21. Guo G, Li Y, Wang HY, et al. Peer Influence, genetic propensity, and binge drinking: A natural experiment and a replication. Am J Sociol. 2015;121(3):914-54.

22. Willemsen G, Vink JM, Abdellaoui A, et al. The adult Netherlands twin register: Twenty-five years of survey and biological data collection. Twin Research and Human Genetics. 2013;16(1):271-81.

23. Huppertz C, Bartels M, Groen-Blokhuis M, et al. The dopaminergic reward system and leisure time exercise behavior: A candidate allele study. BioMed Journal International. 2014;591717.

24. Hiemstra M, Engels CM, Barker ED, et al. Smokingspecific parenting and smoking onset in adolescence: The role of genes from the dopaminergic system (DRD2, DRD4, DAT1 genotypes). PloS ONE. 2013;8(4):e61673.

25. Van der Vorst H, Engels RC, Meeus W, et al. The role of alcohol-specific socialization in adolescents' drinking behaviour. Addiction. 2005;100(10):1464-76.

26. Hiemstra M, Kleinjan M, van Schayck OC, et al. Environmental smoking and smoking onset in adolescence: The role of dopamine-related genes. Findings from two longitudinal studies. PLoS ONE. 2014;9(1):e86497.

27. Heatherton TF, Kozlowski LT, Frecker RC, et al. The fagerström test for nicotine dependence: A revision of the fagerstrom tolerance questionnaire. British Journal of Addiction. 1991;86(9): 1119-27.

28. Vink JM, Willemsen G, Beem AL, et al. The fagerstrom test for nicotine dependence in a Dutch sample of daily smokers and ex-smokers. Addictive Behaviors. 2005;30(3):575-9.

29. Mayfield D, McLeod G, Hall P. The CAGE questionnaire: Validation of a new alcoholism screening instrument. Am J Psychiatry. 1974;131(10):1121-23.

30. Aertgeerts B, Buntinx F, Bande Knops J, et al. The value of CAGE, CUGE and AUDIT in screening for alcohol abuse and dependence among college freshmen. Alcoholism: Clinical and Experimental Research. 2000;24(1):53-7.

31. Buchsbaum DG, Buchanan RG, Centor RM, et al. Screening for alcohol abuse using CAGE scores and likelihood ratios. Ann Intern Med. 1991;115(10):774-7.

32. White HR, Labouvie EW. Towards the assessment of adolescent problem drinking. J Stud Alcohol. 1989;50(1):30-7.

33. White H, Labouvie E. Longitudinal trends in problem drinking as measured by the Rutgers Alcohol Problem Index. Alcoholism: Clinical and Experimental Research. 2000;24:76A.

34. Danielson CK, Overholser JC, Butt ZA. Association of substance abuse and depression among adolescent psychiatric inpatients. Can J Psychiatry. 2003;48(11):7625.

35. Thombs DL, Beck KH. The social context of four adolescent drinking patterns. Health Educ Res. 1994;9(1):13-22.

36. Watt M, Stewart S, Birch C, et al. Brief CBT for high anxiety sensitivity decreases drinking problems, relief alcohol outcome expectancies, and conformity drinking motives: Evidence from a randomized controlled trial. J Ment Health. 2006;15(6):683-95.

37. Myerholtz L, Rosenberg H. Screening college students for alcohol problems: Psychometric assessment of the SASSI-2 substance abuse subtle screening inventory. J Stud Alcohol. 1998;59(4):439-46.

38. Ioannidis JP, Trikalinos TA, Khoury MJ. Implications of small effect sizes of individual genetic variants on the design and interpretation of genetic association studies of complex diseases. Am J Epidemiol. 2006;164(7):609-14.

39. So HC, Gui AH, Cherny SS, et al. Evaluating the heritability explained by known susceptibility variants: A survey of ten complex diseases. Genet Epidemiol. 2011;35(5):310-7.

40. Latvala A, Dick DM, Tuulio-Henriksson A, et al. Genetic correlation and gene-environment interaction between alcohol problems and educational level in young adulthood. J Stud Alcohol Drugs. 2011;72(2):210-20.

41. Vink JM. Genetics of addiction: Future focus on gene $\mathrm{x}$ environment interaction? J Stud Alcohol Drugs. 2016;77(5):684-7.

42. Creemers HE, Harakeh Z, Dick D, et al. DRD2 and DRD4 in relation to regular alcohol and cannabis use among adolescents: Does parenting modify the impact of genetic vulnerability? The TRAILS study. Drug Alcohol Depend. 2011;115(1-2):35-42

43. Lind PA, Eriksson CJ, Wilhelmsen KC. Association between harmful alcohol consumption behavior and dopamine transporter (DAT1) gene polymorphisms in a male Finnish population. Psychiatr Genet. 2009;19(3):117-25.

44. Rasmussen H, Bagger Y, Tanko LB, et al. Lack of association of the serotonin transporter gene promoter region polymorphism, 5-HTTLPR, including rs25531 with cigarette smoking and alcohol consumption. Am J Med Genet B Neuropsychiatr Genet. 2009;150B(4):575-80.

45. Stringer S, Minica CC, Verweij KJ, et al. Genome-wide association study of lifetime cannabis use based on a large meta-analytic sample of 32330 subjects from the International Cannabis Consortium. Transl Psychiatry. 2016;6:e769.

46. The Tobacco and Genetics Consortium. Genome-wide meta-analyses identify multiple loci associated with smoking behavior. Nat Genet. 2010;42(5):441-7.

47. Schumann G, Liu CO,'Reilly P, et al. KLB is associated with alcohol drinking and its gene product $\beta$-Klotho is necessary for FGF21 regulation of alcohol preference. Proc Natl Acad Sci. 2016;201611243. 
Citation: Pasman JA, Verweij KJH, Treur JL, et al. Hypodopaminergic polygenic risk for polysubstance use. J Psychol Cognition. 2017;2(2):138-148.

48. Bierut LJ, Stitzel JA, Wang JC, et al. Variants in nicotinic receptors and risk for nicotine dependence. Am J Psychiatry. 2008;165(9):1163-71.

49. Treutlein J, Rietschel M. Genome-wide association studies of alcohol dependence and substance use disorders. Curr Psychiatry Rep. 2011;13(2):147-55.

50. Sullivan PF. Spurious genetic associations. Biol Psychiatry. 2007;61(10):1121-6.

51. Stenbacka M. Problematic alcohol and cannabis use in adolescence: Risk of serious adult substance abuse? Drug Alcohol Rev. 2003;22(3):277-86.

52. Laucht M, Becker K, Frank J, et al. Genetic variation in dopamine pathways differentially associated with smoking progression in adolescence. Journal of the American Academy of Child and Adolescent Psychiatry. 2008;47(6):673-81.

53. Herman AI, DeVito EE, Jensen KP, et al. Pharmacogenetics of nicotine addiction: Role of dopamine. Pharmacogenomics. 2014;15(2):221-34.

54. Schacht JP, Anton RF, Voronin KE, et al. Interacting effects of naltrexone and OPRM1 and DAT1 variation on the neural response to alcohol cues. Neuropsychopharmacology. 2013;38(3):414-22.

55. Stolf AR, Szobot CM, Halpern R, et al. Crack cocaine users show differences in genotype frequencies of the $3^{\prime}$ UTR variable number of tandem repeats of the dopamine transporter gene (DAT1/SLC6A3). Neuropsychobiology. 2014;70(1):44-51.

56. Munafo MR, Johnstone EC, Guo B, et al. Association of COMT Val108/158Met genotype with smoking cessation. Pharmacogenetics and Genomics. 2008;18(2):121-8.

57. Munafo M, Clark T, Johnstone E, et al. The genetic basis for smoking behavior: A systematic review and metaanalysis. Nicotine and Tobacco Research. 2004;6(4):58397.

58. Smith L, Watson M, Gates S, et al. Meta-analysis of the association of the Taq1A polymorphism with the risk of alcohol dependency: A HuGE gene-disease association review. American Journal of Epidemiology. 2008;167(2):125-38.

59. Esposito-Smythers C, Spirito A, Rizzo C, et al. Associations of the DRD2 TaqIA polymorphism with impulsivity and substance use: Preliminary results from a clinical sample of adolescents. Pharmacology, Biochemistry and Behavior. 2009;93(3):306-12.

60. Hallikainen T, Hietala J, Kauhanen J, et al. Ethanol consumption and DRD2 gene TaqI a polymorphism among socially drinking males. American Journal of Medical Genetics Part A. 2003;119A(2):152-5.

61. McGeary J. The DRD4 exon 3 VNTR polymorphism and addiction-related phenotypes: A review. Pharmacology, Biochemistry \& Behavior. 2009;93(3):222-9.
62. Olsson CA, Moyzis RK, Williamson E, et al. Geneenvironment interaction in problematic substance use: Interaction between DRD4 and insecure attachments. Addiction Biology. 2013;18(4):717-26.

63. Comings DE, Gonzalez N, Wu S, et al. Studies of the $48 \mathrm{bp}$ repeat polymorphism of the DRD4 gene in impulsive, compulsive, addictive behaviors: Tourette syndrome, ADHD, pathological gambling, and substance abuse. American Journal of Medical Genetics Part B: Neuropsychiatric Genetics. 1999;88:11.

64. Gezondheidsraad. Richtlijnen gezonde voeding 2015. Den Haag: Gezondheidsraad, publicationnr. 2015;24.

65. Sullivan PF, Neale MC, Silverman MA, et al. An association study of DRD5 with smoking initiation and progression to nicotine dependence. American Journal of Medical Genetics Part B: Neuropsychiatric Genetics. 2001;105:7.

66. Vanyukov MM, Maher BS, Ferrell RE, et al. Association between the dopamine receptor D5 gene and the liability to substance dependence in males: A replication. Journal of Child \& Adolescent Substance Abuse. 2001;10(4):5563.

67. Kleinjan M, Poelen EA, Engels RC, et al. Dual growth of adolescent smoking and drinking: Evidence for an interaction between the mu $\square$ opioid receptor (OPRM1) A118G polymorphism and sex. Addiction Biology. 2013;18(6):1003-12.

68. Miranda R, Ray L, Justus A, et al. Initial evidence of an association between OPRM1 and adolescent alcohol misuse. Alcoholism: Clinical and Experimental Research. 2010;34(1):112-122.

69. Zhang H, Luo X, Kranzler HR, et al. Association between two $\mu$-opioid receptor gene (OPRM1) haplotype blocks and drug or alcohol dependence. Human Molecular Genetics. 2006;15(6):807-19.

70. Du Y, Wan YJY. The interaction of reward genes with environmental factors in contribution to alcoholism in Mexican Americans. Alcoholism: Clinical and Experimental Research. 2009;33(12):2103-12.

71. Schinka J, Town T, Abdullah L, et al. A functional polymorphism within the $\mu$-opioid receptor gene and risk for abuse of alcohol and other substances. Molecular Psychiatry. 2002; 7:224-8.

72. Enoch MA, Waheed JF, Harris CR, et al. Sex differences in the influence of COMT Val158Met on alcoholism and smoking in plains American Indians. Alcoholism: Clinical and Experimental Research. 2006;30(3):399-406.

73. Isir ABB, Oguzkan S, Nacak M, et al. The catecholO-methyl transferase Val158Met polymorphism and susceptibility to cannabis dependence. The American Journal of Forensic Medicine and Pathology. 2008;29(4):320-2.

74. Beuten J, Payne TJ, Ma JZ, et al. Significant association 
of catechol-O-methyltransferase (COMT) haplotypes with nicotine dependence in male and female smokers of two ethnic populations. Neuropsychopharmacology. 2006;31(3):675-84.

75. Hendershot CS, Lindgren KP, Liang T, et al. COMT and ALDH2 polymorphisms moderate associations of implicit drinking motives with alcohol use. Addiction Biology. 2012;17(1):192-201.

76. Verdejo-García A, Fagundo AB, Cuenca A, et al. COMT val158met and 5-HTTLPR genetic polymorphisms moderate executive control in cannabis users. Neuropsychopharmacology. 2013;38(8):1598-606.

77. Wiesbeck GA, Wodarz N, Weijers HG, et al. A functional polymorphism in the promoter region of the monoamine oxidase: A gene is associated with the cigarette smoking quantity in alcohol-dependent heavy smokers. Neuropsychobiology. 2006;53(4):181-5.

78. Nilsson KW, Comasco E, Åslund C, et al. MAOA genotype, family relations and sexual abuse in relation to adolescent alcohol consumption. Addiction Biology. 2011;16(2):347-55.

79. Gade R, Muhleman D, Blake H, et al. Correlation of length of VNTR alleles at the X-linked MAOA gene and phenotypic effect in Tourette syndrome and drug abuse. Molecular Psychiatry. 1998;3(1):50-60.

80. Jin $\mathrm{Y}$, Chen $\mathrm{D}, \mathrm{Hu} \mathrm{Y}$, et al. Association between monoamine oxidase gene polymorphisms and smoking behaviour in Chinese males. The International Journal of Neuropsychopharmacology. 2006;9(05):557-64.

81. Samochowiec A, Chec M, Kopaczewska E, et al. Monoamine oxidase a promoter variable number of tandem repeats (MAOA-uVNTR) in alcoholics according to Lesch typology. International Journal of Environmental Research and Public Health. 2015;12(3):3317-26.

82. Vanyukov MM, Maher BS, Devlin B, et al. The MAOA promoter polymorphism, disruptive behavior disorders, and early onset substance use disorder: Gene-environment interaction. Psychiatric Genetics. 2007;17(6):323-32.

\section{*Correspondence to:}

Joelle A Pasman

Developmental Psychopathology

Behavioural Science Institute

Radboud University Nijmegen

Nijmegen

The Netherlands

Tel: 243612504

E-mail: j.pasman@bsi.ru.nl 